\title{
Biochemical and histological assessment of hepatic lipid in sudden infant death syndrome
}

\author{
SR CAIRNS,${ }^{*}$ M THOMSOM,${ }^{*}$ AM LAWSON,$\dagger$ MJ MADIGAN $†$ S VARIEND $\ddagger$ TJ PETERS* \\ From the Divisions of *Clinical Cell Biology and †Clinical Chemistry, MRC Clinical Research Centre, \\ Harrow, Middlesex and $\ddagger$ Department of Pathology, Children’s Hospital, Sheffield, Yorkshire
}

SUMMARY A biochemical and histological study of hepatic lipid in children dying from the sudden infant death syndrome (SIDS) and children of a similar age dying explicably are reported. Contrary to a previous report based on histological assessment of hepatic lipid, no significant increase of total lipid content in livers of children dying from SIDS was found. Analysis of hepatic phospholipid fatty acid esters, however, revealed a significant difference between SIDS and children of similar age dying acutely and explicably. The phospholipid abnormality found in SIDS was similar to that found in children dying subacutely with hypoxia and would be consistent with increased cell membrane fluidity. The implications of these findings in the pathogenesis of SIDS are discussed.

Sudden infant death syndrome (SIDS) is the most common cause of death during infancy and accounts for approximately one thousand deaths each year in Great Britain. ${ }^{1}$ Previously, it was assumed that SIDS infants had normal health and development prior to their sudden death although many were noted to have had a mild upper respiratory tract infection during the few days immediately preceding death. Recent research indicates that numerous respiratory factors predispose to $\operatorname{SIDS}^{23}$ and that these infants are in fact not entirely normal prior to death. SIDS babies have decreased respiratory tidal volumes and prolonged apnoea during non-rapid-eye-movement sleep. ${ }^{45}$ In addition it may be that their vagus nerves are immature, reducing the child's response to hypoxia. $^{6}$

Necropsy findings in SIDS indicate chronic hypoxia, ${ }^{7}$ retardation in growth rates and evidence of a metabolic upset with development of fatty liver. ${ }^{8}$ We have recently developed micromethods for lipid analysis suitable for human liver biopsies ${ }^{9}$ and recently reported differences in the nature of hepatic lipid in fatty livers of different aetiology. ${ }^{10} \mathrm{~A}$ previous report based on histological assessment of fatty liver in children with SIDS by Sinclair-Smith et al $^{8}{ }^{8}$ prompted us to make a qualitative and quantitative analysis of hepatic lipid to confirm these findings and investigate further the metabolic disturbance in this disorder.

Accepted for publication 1 June 1983

\section{Material and methods}

The main clinical, histological and biochemical dat are given in Table 1 . Necropsy specimens of live from 20 infants were analysed. Infants 1-4 died acutely and explicably, infants 5-9 died subacutely, that is, after a prolonged illness usually associated with a congenital anomaly and chronic hypoxia Infants $10-20$ died suddenly and inexplicably, socalled cot death or SIDS. The normal adult liver biopsies were obtained with a Tru-Cut needle from patients suspected of having liver disease but in whom subsequent liver histology and serum liver function tests were normal. Tissue was stored at $-20^{\circ} \mathrm{C}$ for subsequent biochemical analysis. Histological assessment was made by studying sections stained with haematoxylin and eosin and with oil red $\mathrm{O}$.

\section{LIPID ANALYSIS}

A portion of each liver biopsy, approximately $10 \mathrm{mg}$, was blotted and rapidly weighed on a torsion balance. The tissue was disrupted at $4^{\circ} \mathrm{C}$ in $0.75 \mathrm{ml}$ of $0.15 \mathrm{~mol} / 1 \mathrm{NaCl}$ in a Duall homogeniser (Kontes Glass Co, Vineland, NJ, USA). An aliquot $(0.25 \mathrm{ml})$ of homogenate was taken for DNA estimation " and the remainder used for lipid analysis. Total phospholipid, free fatty acid, triglyceride, free and esterified cholesterol were separated by thin layer chromatography and measured, with an internal standard, by specific chemical microassays. ${ }^{9}$ 
Table 1 Summary of clinical, histological and biochemical data in patients

\begin{tabular}{|c|c|c|c|c|c|c|}
\hline Infant & $\begin{array}{l}\text { Age at death } \\
\text { (mths) }\end{array}$ & Sex & Feeding & Cause of death & Liver histology & $\begin{array}{l}\text { Hepatic triglyceride } \\
\text { ( } \mu \mathrm{mol} / \mathrm{mg} \text { DNA) }\end{array}$ \\
\hline \multicolumn{7}{|c|}{ Explicable sudden death } \\
\hline 1 & 7 & $\mathbf{F}$ & Breast & Pneumonia & Normal & $5 \cdot 7$ \\
\hline 2 & 5 & $\mathbf{F}$ & Breast & Extradural haematoma & Fat: moderate & $12 \cdot 4$ \\
\hline 3 & 6 & $\mathbf{M}$ & Bottle & $\begin{array}{l}\text { Meningitis } \\
\text { Down's syndrome }\end{array}$ & Fat: minimal & $13 \cdot 5$ \\
\hline 4 & 12 & $\mathbf{M}$ & Bottle & $\begin{array}{l}\text { Acute respiratory } \\
\text { obstruction }\end{array}$ & Normal & $8 \cdot 0$ \\
\hline \multicolumn{7}{|c|}{ Explicable subacute death } \\
\hline 5 & 7 & $\mathbf{F}$ & Bottle & $\begin{array}{l}\text { Primary endocardial } \\
\text { fibro-elastosis }\end{array}$ & Fat: moderate & $21 \cdot 5$ \\
\hline 6 & 6 & $\mathbf{F}$ & Bottle & $\begin{array}{l}\text { Transposition of the } \\
\text { great vessels } \\
\text { (postoperative death) }\end{array}$ & Normal & $2 \cdot 2$ \\
\hline 7 & 9 & $\mathbf{M}$ & Bottle & Fallot's tetralogy & Fat: severe & $41 \cdot 2$ \\
\hline 8 & 4 & $\mathbf{M}$ & Bottle & $\begin{array}{l}\text { Ostium primum with } \\
\text { mitral atresia }\end{array}$ & Fat: moderate & $18 \cdot 7$ \\
\hline 9 & 12 & $\mathbf{M}$ & Bottle & $\begin{array}{l}\text { Dehydration } \\
\text { gastroenteritis }\end{array}$ & Fat: moderate & $27 \cdot 4$ \\
\hline \multicolumn{7}{|c|}{ Sudden inexplicable death } \\
\hline 10 & 5 & $\mathbf{M}$ & Bottle & SIDS & Fat: minimal & $12 \cdot 5$ \\
\hline 11 & 2 & $\mathrm{~F}$ & Breast & SIDS & Normal & $12 \cdot 0$ \\
\hline 12 & 1 & $\mathbf{M}$ & Breast & SIDS & Fat: minimal & $14 \cdot 5$ \\
\hline 13 & 13 & $\mathbf{M}$ & Bottle & SIDS & Fat: moderate & $12 \cdot 7$ \\
\hline 14 & 3 & $\mathbf{M}$ & Breast & SIDS & Normal & $3 \cdot 5$ \\
\hline 15 & 2 & $\mathbf{M}$ & Breast & SIDS & Fat: severe & $12 \cdot 1$ \\
\hline 16 & 3 & $\mathbf{F}$ & Breast & SIDS & Fat: minimal & $8 \cdot 7$ \\
\hline 17 & 3 & $\mathbf{F}$ & Breast & SIDS & Fat: minimal & $5 \cdot 5$ \\
\hline 18 & 2 & $\mathbf{F}$ & Bottle & SIDS & Fat: moderate & $18 \cdot 6$ \\
\hline 19 & 11 & $\mathbf{M}$ & Breast and bottle & SIDS & Fat: severe & $34 \cdot 6$ \\
\hline 20 & 6 & $\mathbf{M}$ & Bottle & SIDS & Fat: minimal & $9 \cdot 2$ \\
\hline
\end{tabular}

SIDS = sudden infant death syndrome.

Fatty acid esters of the major lipids were transmethylated and measured by gas liquid chromatography ${ }^{12}$ for four livers from each group of infants (infants 1-4, 5-8, 10-13).

\section{Results}

All infants died before the age of 13 months. There was a random sex distribution and method of feeding. Infants 1-9 had a readily identifiable cause of death but necropsy failed to identify abnormalities sufficient to cause death in infants $10-20$. Light microscopy revealed apparent hepatic steatosis in most of the livers, particularly in the livers of infants dying subacutely.

\section{MAJOR LIPID CLASSES}

Table 2 shows the major hepatic lipids of infants and normal adults. In molar terms phospholipid is the major lipid comprising approximately half of the recovered lipid in all samples. Similar levels of free cholesterol and free fatty acids were found in all infant livers. However, the levels were significantly greater than that found in normal adult livers. No significant differences were found for the other lipid classes, but the mean triglyceride level was highest in the infants dying subacutely. Phospholipid:free cholesterol ratios (Table 3) were similar in all infant groups and lower in infant livers than normal adult livers.

Table 2 Measurement of major lipid classes of infant and normal adult livers

\begin{tabular}{|c|c|c|c|c|c|}
\hline & Free cholesterol & Cholesterol esters & Phospholipid & Free fatty acid & Triglyceride \\
\hline $\begin{array}{l}\text { Explicable sudden death } \\
(n=4)\end{array}$ & $7.4 \pm 1.8^{*}$ & $0.14 \pm 0.01^{*}$ & $31 \cdot 7 \pm 7 \cdot 5$ & $14 \cdot 9 \pm 2 \cdot 6^{* *}$ & $9.9 \pm 1.8$ \\
\hline $\begin{array}{l}\text { Explicable sub-acute death } \\
(n=5)\end{array}$ & $8 \cdot 4 \pm 1 \cdot 6^{* * *}$ & $0.47 \pm 0.13$ & $31 \cdot 1 \pm 5 \cdot 0$ & $15 \cdot 3 \pm 2 \cdot 7^{* *}$ & $23 \cdot 1 \pm 8 \cdot 1^{*}$ \\
\hline $\begin{array}{l}\text { SIDS }(n=11) \\
\text { Normal adult }(n=7)\end{array}$ & $\begin{array}{l}6.5 \pm 0.7^{* * *} \\
3 \cdot 0 \pm 0.6\end{array}$ & $\begin{array}{l}0 \cdot 26 \pm 0 \cdot 05 \\
0.40 \pm 0 \cdot 10\end{array}$ & $\begin{array}{l}26 \cdot 5 \pm 2.3 \\
23 \cdot 5 \pm 3 \cdot 6\end{array}$ & $\begin{aligned} 14.0 & \pm 1.4^{* *} \\
8.7 & \pm 0.8\end{aligned}$ & $\begin{array}{r}13 \cdot 1 \pm 2.5 \\
8.9 \pm 2.0\end{array}$ \\
\hline
\end{tabular}

Results show mean \pm SE lipid composition $\mu \mathrm{mol} / \mathrm{mg}$ DNA.

Values of normal adult livers from reference 9.

Statistical analysis by Student's $t$ test between normal adults and infant groups: ${ }^{*} p<0.05 ;{ }^{* *} p<0 \cdot 01 ;{ }^{* *} p<0 \cdot 005$. 
Table 3 Double bond index:saturated fatty acid ratios and phospholipid:free cholesterol ratios of infant and normal adult livers

\begin{tabular}{|c|c|c|c|}
\hline & Phospholipid & Triglyceride & Phospholipid:free cholesterol \\
\hline $\begin{array}{l}\text { SIDS } \\
\text { Acute, explicable infant deaths } \\
\text { Sub-acute, explicable infant deaths } \\
\text { Normal adults }\end{array}$ & $\begin{array}{l}2 \cdot 53 \pm 0.21^{*}(4) \\
1 \cdot 71 \pm 0.08(4) \\
2 \cdot 33 \pm 0.37(4) \\
1 \cdot 12 \pm 0.09(10)\end{array}$ & $\begin{array}{l}0.99 \pm 0.18(4) \\
0.91 \pm 0.16(4) \\
1.29 \pm 0.29(4) \\
1.63 \pm 0.15(6)\end{array}$ & $\begin{array}{l}4.32 \pm 0.44(10) \\
4.49 \pm 0.56(4) \\
3.96 \pm 0.56(6) \\
7.91 \pm 0.62(7)\end{array}$ \\
\hline
\end{tabular}

Statistical analysis by Student's $t$ test between SIDS and acute, explicable death groups: ${ }^{*} p<0 \cdot 02$. Results expressed as mean \pm SE. Number of subjects in parentheses.

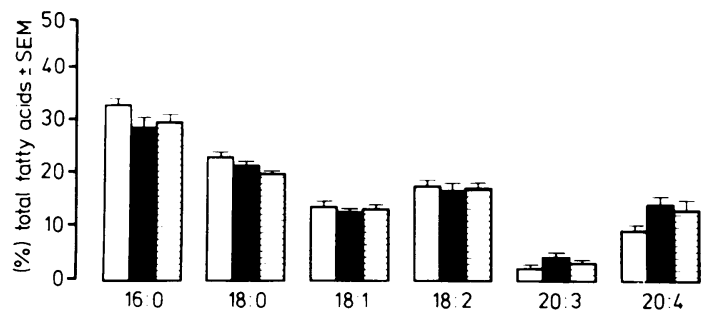

Fig. 1 Hepatic phospholipid fatty acid ester composition $( \pm S E M)$ of infants dying suddenly and explicably $(\square n=4)$, from $\operatorname{SIDS}(\square n=4)$, and infants dying subacutely and explicably $(\in n=4)$.

\section{PHOSPHOLIPID FATTY ACID ESTERS Fig. 1}

Palmitate (16:0) was the major phospholipid fatty acid ester, comprising approximately $30 \%$ of the total fatty acid esters. The proportion of arachidonate, approximately $12 \%$, was similar to that found in normal adult livers. Eicosatrienoic acid (20:3) was found in all infant livers and comprised approximately $5 \%$ of the total fatty acid esters. Fig. 2 compares the mass spectrometric analysis of the authentic ester with the appropriate fatty acid fraction from the phospholipid analysis. This fatty acid was not found in liver from adults. Although

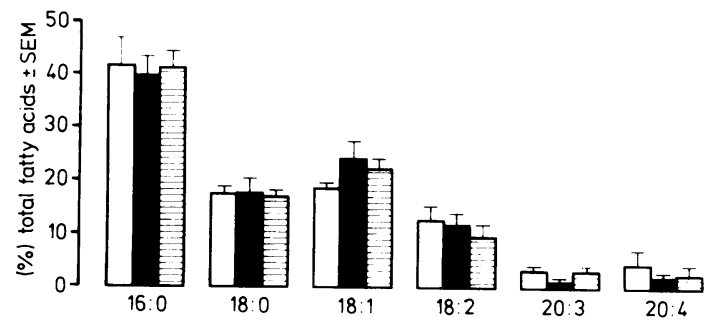

Fig. 3 Hepatic free fatty acid composition ( $\pm S E M)$ of infants dying suddenly and explicably $(\square n=4)$, from SIDS $(\square n=4)$ and infants dying subacutely and explicably (巨 $n=4)$.

there were no significant differences in the proportions of individual fatty acid esters between the various groups of livers, determination of the doubleog bond index: saturated fatty acid ratio revealed significant difference between livers of children? dying suddenly and explicably and those with SIDS (Table 3 ). This ratio is obtained by dividing the double bond index, that is, the sum of the products of the percentage of each unsaturated fatty acid and the number of double bonds, by the percentage of saturated fatty acids. ${ }^{13}$

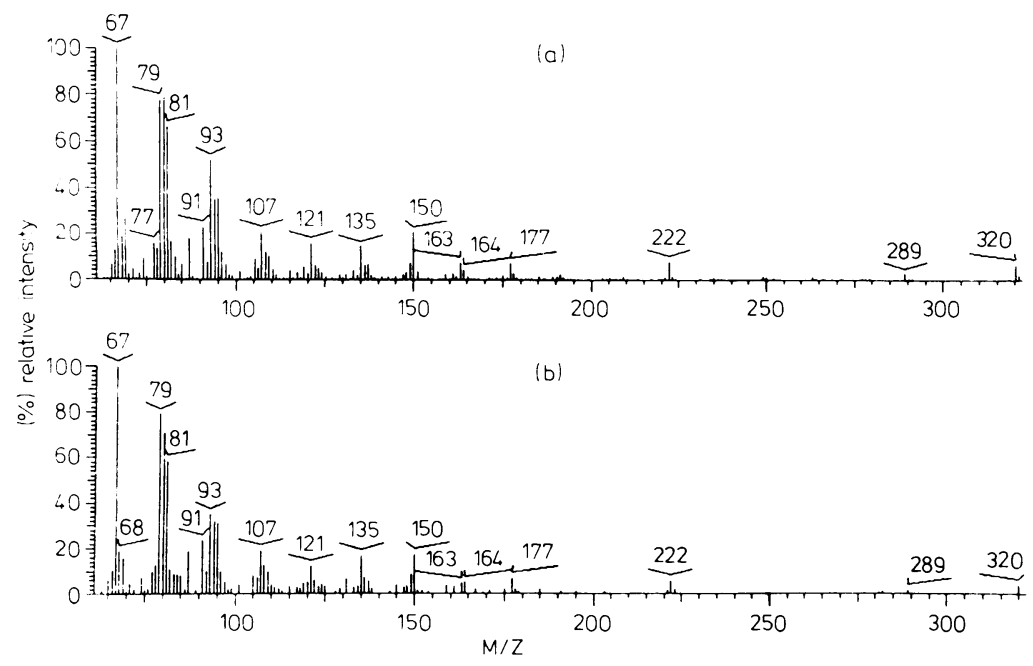

Fig. 2 Mass spectrum of (a) methyl ester derivative of authentic 8, 11, 14-eicosatrienoic acid, and (b) "unknown" fatty acid ester isolated from phospholipid of infant liver. 


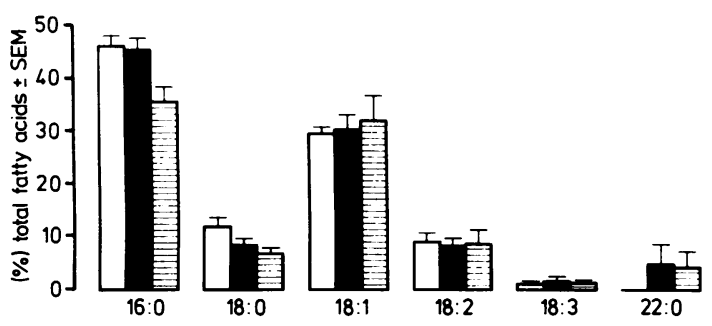

Fig. 4 Hepatic triglyceride fatty acid ester composition ( $\pm S E M)$ of infants dying suddenly and explicably $(\square n=4)$, from SIDS ( $n=4)$, and infants dying subacutely and explicably (目 $n=4$ ).

FREE FATTY ACIDS Fig. 3

Palmitate (16:0) was the major free fatty acid comprising approximately $40 \%$ of the total detected. Proportions of individual fatty acids were similar in all infant livers. Eicosatrienoic acid was present in this lipid fraction of infant livers but was not in livers from adults.

TRIGLYCERIDE FATTY ACID ESTERS Fig. 4

Palmitate (16:0) was the major fatty acid comprising approximately $40 \%$ of the total triglyceride fatty acid esters. No significant differences were found in the proportions of the individual fatty acid esters. The double bond index:saturated fatty acid ratio was similar in all infant livers but tended to be lower than adults (Table 3 ).

\section{CHOLESTER YL ESTER Fig. 5}

No significant differences in the proportions of the individual fatty acids was found although in all except the SIDS livers palmitate (16:0) was the major fatty acid ester. Eicosatrienoic acid was found only in infant liver and comprised approximately $8 \%$ of total fatty acid esters.

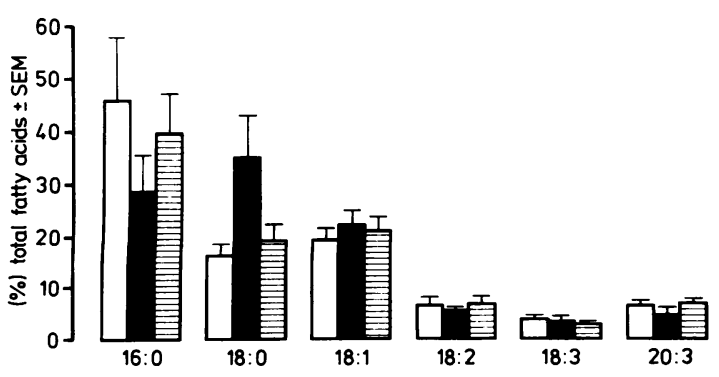

Fig. 5 Hepatic cholesterol fatty acid ester composition $( \pm S E M)$ of infants dying suddenly and explicably $(\square n=4)$, from SIDS $(\square n=4)$ and infants dying subacutely and explicably (固 $n=4)$.

\section{Discussion}

This study reports the first comprehensive hepatic lipid analysis of infant liver and suggests, contrary to a previous report based on histological assessments, that the livers of children dying from SIDS do not contain significantly more lipid than normal children of this age. We have assumed that the hepatic lipid content of the children who died acutely and explicably (infants 1-4) was normal and this contention is supported by the fact that levels of hepatic lipid were similar to the normal adult range.$^{10}$ The highest levels of hepatic triglyceride were seen in those children dying subacutely and explicably. However, no significant differences were found between the different groups of infant livers for any of the major lipids. Postmortem lipolysis could explain the higher free fatty acid levels found in infant livers compared to adult livers which were obtained by needle biopsy from living patients. The mean interval between death and liver biopsy for the infants was 24 hours.

Analysis of the fatty acid esters of the major lipid classes revealed no significant differences between the proportions of individual fatty acid esters in the infant livers from the three patient groups. However, determination of the phospholipid double bond index:saturated fatty acid ratio revealed a significant difference between SIDS and explicable acute death. This ratio is a reflection of membrane fluidity ${ }^{14}$ and regulates the activity of several membrane bound enzymes. ${ }^{15}$ The ratio was lowest in children dying acutely and explicably, and highest in children dying with SIDS. Children dying subacutely and explicably, usually with chronic hypoxia also had higher values than controls. These findings suggest an increased fluidity of liver membranes in SIDS and children dying subacutely and explicably. It remains to be established if the alterations found in hepatic phospholipid also occur in other organs. Biochemical analysis of pulmonary surfactant phospholipid from SIDS showed raised proportions of the polyunsaturated fatty acid esters, suggesting increased surfactant fluidity. ${ }^{16}$ It is therefore likely that the lipid composition of type 2 pneumocytes, where surfactant is produced and secreted, is also abnormal.

The presence of fatty acid ester 20:3 was an unexpected finding since this fatty acid was not found in adult livers. It was established by gas chromatography-mass spectrometry to be the 8 , 11,14 isomer, the immediate precursor of arachidonate in the synthetic pathway from linoleate to arachidonate. Higher levels of 20:3 fatty acid found in infant livers may result from an immaturity in the desaturase pathway converting 20:3 to arachidonate $(20: 4)$. Further studies are required to confirm this 
suggestion but relative immaturity of other liver microsomal pathways in infants has already been established. ${ }^{17}$

Our results show that SIDS babies and children dying subacutely and explicably have a similar abnormality of hepatic phospholipid, suggesting that there is a metabolic disturbance common to both groups. These findings are unlikely to be due to postmortem changes since there was no significant difference in the time interval between death and necropsy for the different groups of infants. Except one, all infants that died subacutely and explicably had a condition associated with chronic hypoxia. Episodic hypoxia has been postulated as the cause of a number of pathological abnormalities found in SIDS. ${ }^{7}$ Our observations demonstrate a metabolic disturbance of phospholipid common to SIDS and subacute death infants supporting the hypothesis that hypoxia may be the metabolic disturbance responsible for some of the abnormalities found in SIDS. SIDS infants had lower hepatic triglyceride concentrations than subacute death infants perhaps reflecting the episodic nature of hypoxia. Alternatively, the abnormal composition of liver membranes in SIDS may be a congenital or postnatal developmental abnormality reflecting susceptibility to sudden death. Clearly further studies investigating membrane composition of various organs in SIDS are indicated.

We are grateful to Ms Rosamund Greensted for secretarial assistance. SRC was in receipt of an MRC Training Fellowship.

\section{References}

' Office of Population Censuses and Surveys, England and Wales, 1980.

${ }^{2}$ Valdes-Depena MA. Sudden Infant Death Syndromes: A review of the medical literature 1974-1979. Pediatrics 1980;66: 597-614.
${ }^{3}$ Shannon DC, Kelly DH. SIDS and near-SIDS. $N$ Engl $J$ Med 1982;306:1022-7.

${ }^{4}$ Haddad GG, Leistner HI, Lai TL, Mellins RB. Ventilation and ventilatory patterns during sleep in aborted sudden infant death syndrome. Pediatr Res 1981;15:1055-7.

${ }^{5}$ Steinschneider A. Prolonged apnea and the sudden infant death syndrome: Clinical and laboratory observations. Pediatrics 1972;50:646-54.

- Sachis PN, Armstrong DL, Becker LE, Bryant AC. The vagus nerve and sudden infant death syndrome: a morphometric study. J Pediatr 1981;98:278-80.

${ }^{7}$ Naeye RL. Sudden Infant Death Syndrome. Sci Am 1980;242:4, 56-62.

${ }^{8}$ Sinclair-Smith C, Dinsdale F, Emery J. Evidence of duration and type of illness in children found unexpectedly dead. Arch Dis Child 1976;51:24-9.

${ }^{9}$ Cairns SR, Peters TJ. Micro-methods for quantitative lipid analysis of human liver needle biopsy specimens. Clin Chim Acta 1983;127:373-82.

${ }^{10}$ Cairns SR, Peters TJ. Biochemical assessment of hepatic lipid in chronic alcoholics, diabetics and control subjects: evidence for an alteration in hepatocyte membrane composition of alcoholics. Clin Sci 1983;64:24P.

"Kapuscinski J, Skoczylas B. Simple and rapid fluorimetric method of DNA assay. Anal Biochem 1977;83:252-7.

${ }_{12}$ Morrison WR, Smith LM. Preparation of fatty acid methyl esters and dimethylacetate from lipids with boron fluoride-methanol. $J$ Lipid Res 1964;5:601-8.

${ }^{13}$ Littleton JM, John ER, Grieve SJ. Alterations in phospholipid composition in ethanol balance and dependence. Alcoholism: Clinical and Experimental Research 1979;3:50-6.

${ }^{14}$ Seelig J, Hasselbach W. A spin label study of sarcoplasmic vesi cles. Eur J Biochem 1971;21:17-21.

is Farias RN, Bloj B, Morero RD, Sineriz F, Trucco RE. Regula tion of allosteric membrane-bound enzymes through change in membrane lipid composition. Biochim Biophys Actä 1975; 415:231-51.

${ }^{16}$ Morley CJ, Brown BD, Hill CM, Barson AJ, Davis JA. Surfactant abnormalities in babies dying from sudden infant death syndrome. Lancet 1982;i:1320-3.

${ }^{17}$ Lathe $\mathrm{GH}$, Walker $\mathrm{M}$. The synthesis of bilirubin glucuronide in animal and human liver. Biochem J 1958;70:705-12.

Requests for reprints to: Dr SR Cairns, Division of Clinical Cell Biology, MRC Clinical Research Centre, Watford Road, Harrow, Middlesex, England. 